\title{
PENGARUH CITRA MREK SUZUKI NEW SATRIA FU150 TERHADAP KEPUTUSAN KONSUMEN
}

\author{
Hermansyah \\ Fakultas Ilmu Sosial dan Ilmu Politik Universitas Kapuas \\ Email: hermansyah.unkas90@gmail.com
}

\begin{abstract}
Abstrak : Penelitian ini dilakukan dengan tujuan untuk mengetahui dan menganalisis: (1). Tanggapan konsumen terhadap Citra Merek Suzuki New Satria FU150 di PT. Indotama Motorika Sintang. (2). Keputusan konsumen dalam membeli Suzuki New Satria FU150 di PT. Indotama Motorika Sintang. (3). Pengaruh Citra Merek terhadap keputusan pembelian Suzuki New Satria FU150 di PT. Indotama Motorika Sintang. Penelitian ini menggunakan rancangan penelitian exsplanatory yang menyoroti hubungan antar variabel independen dengan variabel dependen dan menguji hipotesis yang telah dirumuskan sebelumnya. Populasi yang digunakan oleh peneliti adalah secara kuantitatif. populasinya adalah rata-rata penjualan motor Suzuki New Satria FU150 dari tahun 2012 dan tahun 2013 sebanyak 134 unit kendaraan. Penetapan ukuran sampelnya dengan rumus Slovin, jumlah sample sebesar 60 orang responden. Pengumpulan data dengan menggunakan kuesioner yang disusun dengan skala Likert

Hasil penelitian yang penulis lakukan mengenai pengaruh Citra Merek Suzuki New Satria FU150 terhadap Keputusan Pembelian pada PT. Indotama Motorika Sintang adalah sebagai berikut: Pertama; Tanggapan responden atas Citra Merek sepeda motor Suzuki New Satria FU150 pada PT. Indotama Motorika Sintang pada saat ini sangat baik. Skor total tanggapan responden terhadap citra merek mempunyai dorongan yang sangat baik yakni sebesar 91,37\% masuk dalam kriteria sangat baik. Kedua Tingkat keputusan pembelian sepeda motor Suzuki New Satria FU150 pada PT. Indotama Motorika Sintang pada saat ini adalah Tinggi yang diambil dari lima indikator yaitu pengenalan masalah, pencarian informasi, pengevaluasian alternatif, keputusan pembelian dan perilaku setelah pembelian. Dimana dari ke lima indikator tersebut memiliki skor total tanggapan responden tentang keputusan pembelian yang konsumen lakukan yaitu sebesar $84.52 \%$. Ketiga. Citra Merek mempunyai pengaruh secara positif dan signifikan terhadap keputusan pembelian sepeda motor Suzuki New Satria FU150 di PT. Indotama Motorika Sintang. Besarnya pengaruh Citra Merek terhadap keputusan pembelian yaitu sebesar $6.8121 \%$ sedangkan sisanya senilai $93.1879 \%$ dipengaruhi oleh faktor lain yang penulis tidak teliti seperti perikanan, promosi, lokasi.
\end{abstract}

Kata Kunci: Citra Merk, Keputusan Konsumen.

PT. Suzuki Indomobil Motor merupakan sebuah perusahaan Penanaman Modal Asing (PMA) yang berdiri dengan kekuatan 5 (Lima) buah perusahaan, yakni PT. Indohero Steel \& Engineering Co, PT. Indomobil Utama, PT. Suzuki Indonesia Manufacturing, PT. Suzuki Engine Industry dan PT. First Chemical Industry. Lima perusahaan tersebut bergabung (Merger) dengan persetujuan dari Presiden Republik Indonesia melalui surat pemberitahuan tentang persetujuan Presiden dari Ketua Badan Koordinasi Penanaman Modal (BKPN) nomor 05 / I PMA / 90 tertanggal 1 Januari 1990, dan diperingati sebagai tanggal berdirinya PT. Indomobil Suzuki International, yang bergerak dalam bidang usaha Industri Komponen dan Perakitan kendaraan bermotor merek Suzuki roda dua (sepeda motor) dan roda empat (mobil).

PT. Indotama Motorika Sintang merupakan daeler resmi Suzuki yang bergerak dalam bidang penjualan roda dua (Motor ), khusus menjual Motor Merek Suzuki dengan berbagai type seperti : FU 150 SCD, FL 125, FW 110, UK 125 SC, UW 125 SC, UD 110 E, UY 125 S, EN 125 NHK, FV 110, GW 250, UF 110. PT. Indotama Motorika Sintang selain menjual Motor khusus Suzuki dilengkapi dengan bengkel resmi untuk perbaikan dan perawatan sepeda motor serta menjual spare part yang asli guna memberikan kemudahan bagi konsumen dalam melakukan perawatan. Merek Suzuki merupakan merek yang sudah mempunyai nama besar sekaligus Citra sebagai motor tangguh dan terpercaya di benak konsumen yang menjadi daya tarik tersendiri dan merek Suzuki bertujuan bukan sebagi daya tarik saja melainkan merek juga digunakan sebagai alat untuk meningkatkan daya saing. Dalam persaingannya Suzuki New Satria FU150 merupakan motor bebek sport berkapasitas $150 \mathrm{cc}$ ini mempunyai nama besar Suzuki dengan citra ketangguhan mesinya dibandingkan motor 
merek lain diharapkan mampu mengambil posisi sebagai penguasa pasar.

Sejalan dengan pemaparan di atas harusnya penjualan Suzuki New Satria FU150 pada PT. Indotama Motorika Sintang juga mengalami kenaikan karena nama besar dan Citra Suzuki yang positif dari konsumen namun berdasarkan data pembeli pada PT. Indotama Motorika Sintang malah terjadi penurunan, sebagaimana terlihat pada table dibawah ini.

Tabel 1. Jumlah Penjualan Kendaraan Suzuki PT. Indotama Motorika Sintang Tahun 2012-2013

\begin{tabular}{|l|l|r|r|}
\hline \multirow{2}{*}{ No. } & \multirow{2}{*}{ Type Kendaraan } & \multicolumn{2}{|c|}{ Volume Penjualan (Unit) } \\
\cline { 3 - 4 } & & Tahun 2012 & Tahun 2013 \\
\hline 1. & FU 150 SCD & 165 & 102 \\
\hline 2 & FL 125 & 21 & 10 \\
\hline 3 & FW 110 & 26 & 8 \\
\hline 4 & UK 125 SC & 8 & 0 \\
\hline 5 & UW 125 SC & 2 & 10 \\
\hline 6 & UD 110 E & 2 & 5 \\
\hline 7 & UY 125 S & 6 & 0 \\
\hline 8 & EN 125 NHK & 0 & 2 \\
\hline 9 & FV 110 & 0 & 1 \\
\hline 10 & GW 250 & 0 & 142 \\
\hline 11 & UF 110 & 263 & 2 \\
\hline Jumlah Penjualan (Unit) & & \\
\hline
\end{tabular}

Sumber : PT. Indotama Motorika Sintang, 2014

Berdasarkan table 1.1 di atas pembelian motor Suzuki New Satria FU150 terlihat, bahwa dalam pembelian motor Suzuki New Satria FU150 terdapat penurunan volume penjualan. Berdasarkan pada uraian latar belakang maka penulis tertarik utuk meneliti lebih jauh tentang pengaruh Citra Merek terhadap keputusan pembelian dengan mengangkat judul "Pengaruh Citra Merek Suzuki New Satria FU150 Terhadap Keputusan Konsumen Pada PT. Indotama Motorika Sintang"

Berdasarkan pada latar belakang yang telah diuraikan tersebut diatas, maka masalah yang diidentifikasi oleh penulis adanya suatu kesenjangan dalam keputusan pembelian konsumen, dan terjadi penurunan pembelian terhadap pembelian sepeda motor Suzuki New Satria FU150. Berdasarkan pada uraian diatas, maka penulis merumuskan masalahnya sebagai berikut:

1. Bagaimana tanggapan konsumen terhadap citra merek Suzuki New Satria FU150 yang ditawarkan di PT. Indotama Motorika Sintang?

2. Bagaimana tingkat keputusan konsumen terhadap pembelian Suzuki New Satria FU150 yang ditawarkan di PT. Indotama Motorika Sintang?

3. Seberapa besarkah pengaruh citra merek terhadap keputusan pembelian Suzuki New Satria FU150 yang ditawarkan di PT. Indotama Motorika Sintang?
Adapun tujuan dari penelitin yang dilakukan dalam menjawab identifikasi masalah adalah:

1. Untuk mengetahui tanggapan konsumen terhadap Citra Merek Suzuki New Satria FU150 di PT. Indotama Motorika Sintang.

2. Untuk mengetahui tingkat keputusan konsumen dalam membeli Suzuki New Satria FU150 di PT. Indotama Motorika Sintang.

3. Untuk mengetahui seberapa besar pengaruh Citra Merek terhadap keputusan pembelian Suzuki New Satria FU150 di PT. Indotama Motorika Sintang.

Merek merupakan nama pada sebuah produk, selain nama pada sebuah produk merek juga merupakan alat untuk ciri dan daya tarik tersendiri pada produk. Penerapan merek yang tepat pada produk dapat memberikan nilai tersendiri dan akan mejadikan identitas pada produk, yang nantinya akan mempunyai citra, baik itu citra yang positif ataupun citra yang negative. Dengan citra yang positif perusahaan akan diuntungkan karna konsumen akan dengan mudah mengingat merek produk bercitra positif sesuai dengan kebutuhannya. Menurut Kotler (2003) yaitu: "Brand is a name, term, sign, symbol, or design, or combination of them, intended to identify the goods and services of one seller or group of sellers and differentiance them from those of competitors". 
Disini menunjukan Merek adalah nama, istilah, tanda, simbol, atau rancangan, atau kombinasi semua unsur tersebut, yang bertujuan untuk mengidentifikasi produk atau jasa dari individual atau kelompok penjual dan untuk membedakannya dari produk pesaing. American Marketing Association diterjemahkan Molan (dalam Kotler, 2005) dijelaskan Merek adalah nama, istilah, tanda, simbol, atau rancangan, atau kombinasi semuanya yang dimaksudkan untuk mengidentifikasi barang atau jasa dari seorang atau sekelompok penjual dan untuk membedakannya dari barang atau jasa pesaing. Kotler dan Armstrong (2003) mengegaskan bahwa Merek adalah suatu nama, kata, tanda, simbol, atau desain, atau kombinasi dari semuanya yang mengidentifikasikan pembuat atau penjual produk dan jasa tertentu.

Menurut Kotler diterjemahkan oleh Molan (2005) Citra merek adalah: Kumpulan keyakinan atau kepercayaan atas merek tertentu. Rangkuti (2002) menyatakan Citra Merek adalah sekumpulan asosiasi merek yang terbentuk di benak konsumen. Solihin (2004) menyatakan bahwa: Citra Merek merupakan segala sesuatu tentang merek suatu produk yang dipikirkan, dirasakan dan divisualisasi oleh konsumen. Selanjutnya Poeradisastra ( 2005), Citra merek positif dapat membantu agar konsumen lebih mudah mengingatnya sehingga mempermudah pengambilan keputusan ketika melakukan pembelian. Hamel dan Prahalad (Kertajaya, 2000) yang mengemukakan bahwa terdapat empat hal pokok yang harus diperhatikan dalam sebuah Merek, agar merek terbentuk dengan baik dan nantinya memberikan citra yang baik, yaitu:. Recognition, Reputation, Affinity, Loyalty. Kotler dan Armstrong (2004) mengemukakan bahwa: keputusan pembelian adalah tahap proses keputusan dimana konsumen secara aktual melakukan pembelian produk. Keputusan pembelian terjadi dipengaruhi oleh berbagai faktor, yaitu faktor dari konsumen sendiri, faktor dari pihak luar, maupun faktor - faktor dari produsen. Dan keputusan pembelian terjadi karena danya berbagi pilihan yang lebih dari satu produk. Kotler diterjemahkan oleh Molan (2005) membagi empat jenis perilaku pembelian konsumen berdasarkan tingkat keterlibatan pembeli dan tingkat perbedaan antara merek, yaitu: 1. Perilaku pembelian yang kompleks (Complex Buying Behaviour); 2. Perilaku pembelian yang mengurangi ketidak efisienan (Dissonance-Reducing Buyer Behaviour); 3. Perilaku pembelian karena kebiasaan (Habitual Buying Behaviour); 4. Perilaku pembeli mencari keragaman (VarietySeeking Buying Behaviour)

Menurut Kotler dan Armstrong (2004) proses pengambilan keputusan pembelian terdiri dari lima tahap: pengenalan kebutuhan, pencarian informasi, pengevaluasian alternatif, keputusan pembelian, dan perilaku setelah pembelian. Dan tahapan proses pembelian suatu produk bila digambarkan akan terbentuk sebagai berikut:

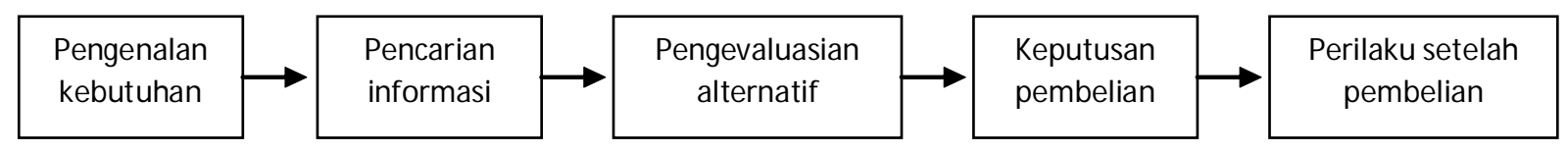

Sumber: Kotler dan Armstrong (2004)

Menurut Poeradisastra (2005), Citra merek positif dapat membantu agar konsumen lebih mudah mengingatnya sehingga mempermudah pengambilan keputusan ketika melakukan pembelian. Berdasarkan pada penjelasan diatas Merek merupakan nama pada sebuah produk, selain nama pada sebuah produk merek juga merupakan alat untuk ciri dan daya tarik tersendiri pada produk. Dan penerapan merek yang tepat pada produk dapat memberikan nilai tersendiri dan akan mejadikan identitas pada produk, yang nantinya akan mempunyai citra, baik itu citra yang positif ataupun citra yang negatif.

\section{METODE PENELITIAN}

Secara garis besar dalam penelitian ini akan digunakan rancangan (design) penelitian exsplanatory (penjelasan), yang menyoroti hubungan antar variabel independen dengan variabel dependen dan menguji hipotesis yang telah dirumuskan sebelumnya. Dalam penelitian ini penulis mengambil lokasi di PT. Indotama Motorika Sintang, mengingat PT. PT. Indotama Motorika merupakan satu-satunya agen motor merk Suzuki yang terdapat di Kabupaten Sintang. Populasi yang digunakan oleh peneliti adalah secara kuantitatif. populasinya adalah ratarata penjualan motor Suzuki New Satria FU150 dari tahun 2012 dan tahun 2013 masing-masing 165 Unit kendaraan dan 102 Kendaraan. Jadi penjualan kendaraan selama 2 tahun sebanyak 267 unit kendaraan. Rata-rata penjualan setiap tahunnya 267 Unit Kendaraan : 2 Tahun $=133,5$ Unit kendaraan. Dan dibulatkan menjadi 134 unit kendaraan.

Ukuran sampelnya, menurut Umar (2005:146) dapat digunakan teknik Slovin, dengan rumus sebagai berikut: 


$$
n=\frac{N}{1+N e^{2}}
$$

Dimana:

$$
\begin{aligned}
& \mathrm{n}= \text { Ukuran Sampel } \\
& \mathrm{N}= \text { Ukuran Populasi } \\
& \mathrm{e}= \begin{array}{l}
\text { Persen kelonggaran ketidak teliti karena } \\
\text { kesalahan pengambilan sampel dalam }
\end{array} \\
& \text { penelitian ini diambil }
\end{aligned}
$$

Teknik pengumpulan data yang penulis gunakan untuk mendapatkan data rresponden, maka penulis menggunakan kuesioner sebagai instrumen pengumpulan datanya. Kuisioner akan disebarkan kepada responden disusun dengan menggunakan skala Likert. Menurut Sugiyono (2008) "skala Likert digunakan untuk mengukur sikap, pendapat, dan persepsi seseorang atau sekelompok orang tentang fenomena sosial". Dengan skala Likert, maka variabel yang akan diukur dijabarkan menjadi indikator variabel. Kemudian indikator tersebut dijadikan sebagai titik tolak untuk menyusun item-item instrumen yang dapat berupa pernyataan atau pertanyaan. Jawaban setiap item istrumen yang menggunakan skala Likert mempunyai gradasi dari sangat positif sampai sangat negatif, yang dapat berupa kata-kata antara lain:

Tabel 2. Skor Atas Jawaban Kuesioner

\begin{tabular}{|c|l|c|}
\hline No. & \multicolumn{1}{|c|}{ Jenis Jawaban } & Skor \\
\hline 1 & Sangat setuju & 5 \\
\hline 2 & Setuju & 4 \\
\hline 3 & Ragu-ragu & 3 \\
\hline 4 & Tidak setuju & 2 \\
\hline 5 & Sangat tidak setuju & 1 \\
\hline
\end{tabular}

Sumber: Sugiyono, 2008

Uji validitas ini bertujuan untuk mengkaji sejauh mana alat ukur, dalam ini kuesioner mengukur apa yang hendak di ukur atau sejauh mana alat ukur yang di gunakan mengenai sasaran. Semakin tinggi validitas suatu alat test, maka alat tersebut semakin mengenai sasarannya, atau senakin menunjukan apa yang seharusnya di ukur. Menurut Sugiyono (2008) menjabarkan Korelasi Rank Spearman sebagai berikut: Korelasi Rank Spearman digunakan untuk mencari hubungan atau untuk menguji signifikansi hipotesis asosiatif bila masing-masing variabel yang dihubungkan berbentuk ordinal, dan sumber data antar variabel tidak harus sama. Adapun rumus Korelasi Rank Spearman adalah sebagai berikut:

$$
r_{s}=1-\frac{6 \sum d_{i}^{2}}{n\left(n^{2}-1\right)}
$$

Menurut Sugiyono (2008) bahwa Item yang mempunyai korelsi positif dengan kriterium (skor total) serta korelasi yang tinggi, menunjukkan bahwa item tersebut mempunyai validitas yang tinggi pula. Biasanya syarat minimum untuk dianggap memenuhi syarat adalah kalau $r=0,3$. Jadi kalau korelasi antara butir dengan skor total kurang dari 0,3 maka butir dalam instrumen tersebut dinyatakan tidak valid. Uji reabilitas di tunjukan untuk menguji sejauh mana suatu hasil pengukuran relatif konsisten apabila pengukuran di ulang dua kali atau lebih jadi reabilitas adalah indeks yang menunjukan sejauh mana alat ukur dapat di percaya atau diandalkan jika alat ukur tersebut digunakan dua kali untuk konsisten. Husein (2005) untuk mencari reliabilitas instrumen yang skornya bukan $0-1$, tetapi merupakan rentangan antara beberapa nilai, misalnya 0-10 atau 0-100 atau bentuk skala 1-3, 1-5 atau 1-7 dan seterusnya dapat menggunakan rumus Cronbach's Alpha dengan menggunakan rumus sebagai berikut :

$$
r_{11}=\left(\frac{k}{k-1}\right)\left(1-\frac{\sum \sigma_{b}^{2}}{\sigma_{t}^{2}}\right)
$$

Dimana:

$$
\begin{aligned}
\mathrm{r}_{11} & =\text { reliabilitas instrument } \\
\mathrm{k} & =\text { banyak butir pertanyaan } \\
& =\text { varians total } \\
& =\text { jumlah varians butir }
\end{aligned}
$$

Untuk mencari varians, digunakan rumus sebagai berikut: 
$\sigma=\frac{\sum X^{2} \frac{\left(\sum X\right)^{2}}{n}}{n}$

Dimana;

$\mathrm{n} \quad=$ jumlah sampel

$\mathrm{X} \quad=$ nilai skor yang dipilih

Menurut Nasution dan Usman (2006) Jika koefisien reabilitas (Alpha) mendekati 1 sangat baik, jika berada diatas 0,8 baik, tetapi bila berada di bawah nilai 0,6 tidak baik. Artinya, bila nilai Alpha berada di bawah 0,6, maka dapat dikatakan bahwa pengukuran yang dilakukan tidak konsisten atau pengukuran kita tidak reliable.

Uji hipotesis, yaitu menentukan ada tidaknya pengaruh (variabel $\mathrm{X}$ ) sebagai variabel bebas terhadap (variabel Y) sebagai variabel tidak bebas/tergantung. Dengan memperhatikan karakteristik variabel yang akan diuji, berdasarkan perumusan hipotesis yaitu :

$\mathrm{H}_{0}: \tilde{\mathrm{n}}=0 \AA \quad$ Tidak ada pengaruh antara Citra Merek terhadap Keputusan Pembelian Konsumen

$\mathrm{H}_{1}: \tilde{\mathrm{n}}$ "“ $\mathrm{O} \circledast \quad$ Adanya pengaruh antara Citra Merek terhadap Keputusan Pembelian Konsumen

Dimana untuk menentukan t hitung, penulis menggunakan rumus signifikan dari Sugiyono (2008), berikut rumus yang dipakai ;

$t=r \sqrt{\frac{n-2}{1-r^{2}}}$
Dimana :

$t=\mathrm{t}$ hitung

$r \quad=$ nilai korelasi Rank Spearman

$n=$ jumlah sample

Dalam menentukan daerah penerimaan dan penolakkan hipotesis nol, dapat diterapkan pada data penelitian distribusi data grafik kurva normal seperti dibawah ini:

Dimana :

1. Dengan tingkat signifikan (á ) $=0,1$

2. Derajat kebebasan $(\mathrm{dk})=\mathrm{n}-2$

Gambar: kurva normal dalam pengujian hipotesis penelitian

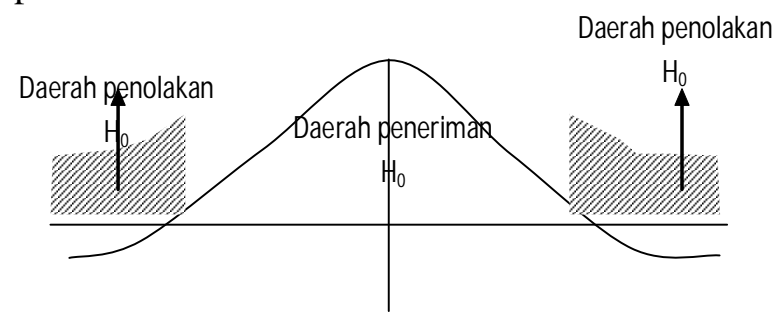

HASIL PENELITIAN DAN PEMBAHASAN

Responden yang menjadi sampel penelitian ini adalah konsumen yang membeli sepeda motor Suzuki New Satria FU150 di PT. Indotama Motorika Sintang. Dalam penelitian ini karakteristik yang akan dipaparkan meliputi: Jenis Kelamin, usia responden, pekerjaan responden, dan pendapatan perbulan responden. Hasil uji validitas dengan program SPSS 19.0 For Windows. Berikut hasil pengujian validitas variabel $\mathrm{X}$ dan variabel $\mathrm{Y}$ :

Tabel 3 Hasil Pengujian Validitas Variabel X dan Variabel Y

\begin{tabular}{|c|c|c|c|}
\hline Item & $\begin{array}{c}\text { Corrected Item-Total } \\
\text { Correlation }\end{array}$ & r kritis & Keterangan \\
\hline P1 & 0.728 & 0.3 & Valid \\
\hline P2 & 0.737 & 0.3 & Valid \\
\hline P3 & 0.731 & 0.3 & Valid \\
\hline P4 & 0.712 & 0.3 & Valid \\
\hline P5 & 0.797 & 0.3 & Valid \\
\hline P6 & 0.737 & 0.3 & Valid \\
\hline P7 & 0.748 & 0.3 & Valid \\
\hline P8 & 0.748 & 0.3 & Valid \\
\hline P9 & 0.744 & 0.3 & Valid \\
\hline P10 & 0.795 & 0.3 & Valid \\
\hline P11 & 0.839 & 0.3 & Valid \\
\hline P12 & 0.771 & 0.3 & Valid \\
\hline P13 & 0.800 & 0.3 & Valid \\
\hline P14 & 0.843 & 0.3 & \\
\hline P15 & 0.795 & & \\
\hline
\end{tabular}

Sumber: Data primer yang telah diolah dengan program SPSS 19.0 For Windows 
Dari tabel diatas dapat disimpulkan bahwa, Instrumen pada variabel $\mathrm{X}$ dan variabel $\mathrm{Y}$ yang penulis ajukan dalam angket cukup representative dalam mewakili objek yang diteliti. Dimana uji validitas semua item $\mathrm{X}$ dan $\mathrm{Y}$ seluruhnya valid dikarenakan $r$ hitung $>\mathrm{r}$ kritis. Hasil uji reliabilitas dengan menggunakan SPSS 19.0 For Windows. diketahui nilai Cronbach's Alpha sebagaimana tertera dalam tabel 3.4 di bawah ini:

Tabel 4 Hasil Pengujian Reliabilitas Variabel X dan Variabel Y

\begin{tabular}{|l|c|c|c|}
\hline \multicolumn{1}{|c|}{ Variabel } & Cronbach's Alpha & r kritis & Keterangan \\
\hline $\begin{array}{l}\text { Variabel X } \\
\text { (Citra Merek) }\end{array}$ & 0.769 & 0.6 & Reliabel \\
\hline $\begin{array}{l}\text { Variabel Y } \\
\text { (Keputusan pembelian) }\end{array}$ & 0.826 & 0.6 & Reliabel \\
\hline
\end{tabular}

Sumber : Data primer yang telah diolah dengan program SPSS 19 For Windows

Dari tabel 4 diatas dapat disimpulkan bahwa, semua Variabel X dan Y dapat dikatakan reliabel, dikarenakan nilai Cronbach's Alpha > r kritis. Dimana nilai Cronbach's Alpha untuk variabel $\mathrm{X}$ sebesar 0,769 >0,6, maka dapat dikatakan reliabel, begitupun untuk nilai Cronbach's Alpha untuk variabel Y sebesar 0,826>0,6. maka variabel
Y inipun dapat dikatakan reliabel. Dari hasil analisis kuesioner terhadap Citra Merek, maka dapat dipaparkan nilai rata-rata kesetujuan dari 60 responden terhadap citra merek dalam keputusan pembelian sepeda motor Suzuki New Satria FU150 di PT. Indotama Motorika Sintang yang telah diolah dapat dilihat pada tabel 5 berikut ini:

Tabel 5 Tanggapan Responden Terhadap Citra Merek

\begin{tabular}{|c|c|c|c|}
\hline No & Indikator & Frekuensi & Persentase $(\%)$ \\
\hline 1 & Recogbition & 479 & $21,84 \%$ \\
\hline 2 & Reputation & 241 & $10.98 \%$ \\
\hline 3 & Affiniti & 944 & $43.04 \%$ \\
\hline 4 & Loyalty & 529 & $24.12 \%$ \\
\hline & Total & 2193 & $100 \%$ \\
\hline
\end{tabular}

Sumber: Data primer yang telah diolah

Analisis deskripsi tentang Citra Merek dapat dilihat pada tabel 6. di bawah ini:

Tabel 6 Skor Tanggapan Responden Terhadap Citra Merek

\begin{tabular}{|c|c|}
\hline Skor Total & Skor dalam Persen \\
\hline 2193 & $\frac{2193}{8 \times 5 \times 60} \times 100 \%=91.37 \%$ \\
\hline
\end{tabular}

Maka dihasilkan data peringkat Citra Merek seperti yang dapat dilihat pada tabel 7 berikut ini:

Tabel 7 Pengkategorian Skor Jawaban

\begin{tabular}{|c|l|}
\hline Interval Tingkat Intensitas & \multicolumn{1}{c|}{ Kriteria } \\
\hline $20 \%-<36 \%$ & Sangat tidak baik \\
\hline $37 \%-<52 \%$ & Tidak baik \\
\hline $53 \%-<68 \%$ & Cukup baik \\
\hline $69 \%-<84 \%$ & Baik \\
\hline $85 \%-<100 \%$ & Sangat baik \\
\hline
\end{tabular}

Sumber: Data primer yang telah diolah 
Berdasarkan tabel 7 diatas menunjukkan bahwa Citra Merek yang dimiliki oleh motor Suzuki New Satria FU150 pada PT. Indotama Motorika Sintang sangat baik. Hal ini terlihat dari tabel 6 dimana skor total dari tanggapan responden tentang Citra Merek sebesar $91.37 \%$ dimana apabila kita lihat dalam tabel 3.7 berada diantara $85 \%-<100 \%$ dengan kriteria sangat baik. Hal ini membuktikan bahwa tingkat Citra Merek yang dimiliki oleh motor
Suzuki New Satria FU150 pada PT. Indotama Motorika Sintang sangat baik.

Berdasarkan hasil analisis kuesioner terhadap keputusan pembelian, maka dapat dipaparkan nilai rata-rata kesetujuan dari 60 responden terhadap keputusan pembelian konsumen dalam membeli sepeda motor Suzuki New Satria FU150 pada PT. Indotama Motorika Sintang yang telah diolah dapat dilihat pada tabel 8 berikut ini:

Tabel 8 Tanggapan Responden Terhadap Tingkat Keputusan Pembelian

\begin{tabular}{|c|l|c|c|}
\hline No & \multicolumn{1}{|c|}{ Indikator } & Frekuensi & Persentase \\
\hline 1 & Pengenalan masalah & 258 & $14.53 \%$ \\
\hline 2 & Pencarian informasi & 506 & $28.50 \%$ \\
\hline 3 & Pengevaluasian alternatif & 504 & $28.39 \%$ \\
\hline 4 & Keputusan pembelian & 244 & $13.74 \%$ \\
\hline 5 & Pasca pembelian & 263 & $14.61 \%$ \\
\hline \multicolumn{2}{|c|}{ Total } & 1775 & $100 \%$ \\
\hline
\end{tabular}

Sumber: Data primer yang telah diolah

Analisis deskripsi tentang keputusan pembelian konsumen dapat dilihat pada Tabel 9 di bawah ini:

Tabel 9 Skor Tanggapan Responden Terhadap Tingkat Keputusan Pembelian

\begin{tabular}{|c|c|}
\hline Skor Total & Skor dalam Persen ( \% ) \\
\hline 1775 & $\frac{1775}{7 \times 5 \times 60} \times 100 \%=84.52 \%$ \\
\hline
\end{tabular}

Maka dihasilkan data peringkat keputusan pembelian konsumen seperti yang dapat dilihat pada tabel 3.10 berikut ini:

Tabel 10 Pengkategorian Skor Jawaban

\begin{tabular}{|c|l|}
\hline Interval Tingkat Intensitas & \multicolumn{1}{c|}{ Kriteria } \\
\hline $20 \%-<36 \%$ & Sangat tidak tinggi \\
\hline $37 \%-<52 \%$ & Tidak tinggi \\
\hline $53 \%-<68 \%$ & Cukup tinggi \\
\hline $69 \%-<84 \%$ & Tinggi \\
\hline $85 \%-<100 \%$ & Sangat tinggi \\
\hline
\end{tabular}

Sumber: Data primer yang telah diolah

Berdasarkan tabel 10 di atas menunjukkan bahwa keputusan pembelian yang terjadi pada pembeli sepeda motor Suzuki New Satria FU150 di PT. Indotama Motorika Sintang adalah tinggi. Hal ini terlihat dari tabel 9 dimana skor total dari tanggapan responden tentang keputusan pembelian sebesar $84.52 \%$ dimana apabila kita lihat dalam tabel 10 berada diantara $69 \%-<84 \%$ dengan kriteria tinggi. Hal ini membuktikan bahwa tingkat keputusan pembelian konsumen yang terjadi pada saat ini pada pembeli sepeda motor Suzuki New Satria FU150 di PT. Indotama Motorika Sintang adalah tinggi.

Uji hipotesis mengenai ada tidaknya pengaruh Citra Merek terhadap keputusan pembelian, dimana untuk mengetahuinya peneliti melakukan pengolahan data dengan analisa korelasi 
spearman rank, koefisiensi diterminasi serta pengujian hipotesis. Untuk mengetahui seberapa kuat hubungan Citra Merek dengan keputusan pembelian, maka dari data-data yang telah diperoleh selama penelitian akan dianalisis dengan menggunakan metode spearman rank, kemudian setelah mengetahui hasil dari perhitungan yang digunakan dengan metode spearman rank yang diolah melalui SPSS 19.0 for windows, maka diperoleh hasil korelasi sebagai berikut:

Tabel 11 Nilai Korelasi Rank Spearman

\begin{tabular}{|lll|r|r}
\hline & & \multicolumn{1}{c|}{$\begin{array}{c}\text { citra } \\
\text { merek }\end{array}$} & $\begin{array}{r}\text { keputusan } \\
\text { pembelian }\end{array}$ \\
\hline $\begin{array}{l}\text { Spearman's } \\
\text { rho }\end{array}$ & citra merek & Correlation & 1.000 & $\mathbf{. 2 6 1}(*)$ \\
& & $\begin{array}{l}\text { Coefficient } \\
\text { Sig. (2-tailed) }\end{array}$ & .044 \\
& $\begin{array}{l}\text { keputusan } \\
\text { pembelian }\end{array}$ & $\begin{array}{l}\text { Correlation } \\
\text { Coefficient }\end{array}$ & $\mathbf{. 2 6 1}(*)$ & $1.000^{*}$ \\
& Sig. (2-tailed) & .044 &. \\
\hline
\end{tabular}

Correlation is significant at the 0.05 level (2-tailed).

a Listwise $\mathrm{N}=60$

Angka pada output antara citra merek dengan keputusan pembelian menghasilkan angka 0,261. Berdasarkan kriteria, angka tersebut bermakna bahwa hubungan kedua variabel rendah, searah dan signifikan $(<0,01)$. Searah artinya jika tingkat citra merek semakin tinggi maka semakin tinggi pula tingkat keputusan pembelian konsumen, atau sebaliknya. Untuk mengetahui lebih jelas mengenai tingkat hubungan antara Citra Merek dengan keputusan pembelian, menurut Sugiyono (2008:250) dapat dilihat pada tabel 3.12 di bawah ini:

Tabel 12 Pedoman Interpretasi Koefisiensi Korelasi

\begin{tabular}{|c|c|}
\hline Interval koefisien & Tingkat Hubungan \\
\hline $0,00-0,199$ & Sangat Rendah \\
\hline $\mathbf{0 , 2 0}-\mathbf{0 , 3 9 9}$ & Rendah \\
\hline $0,40-0,599$ & Sedang \\
\hline $0,60-0,799$ & Kuat \\
\hline $0,80-1,000$ & Sangat kuat \\
\hline
\end{tabular}

Sumber: Sugiyono, 2008

Untuk mengetahui besaran pengaruh Citra Merek terhadap keputusan pembelian, maka digunakan rumus:

$$
\begin{aligned}
& K d=r^{2} \times 100 \% \\
& K d=0,261^{2} \times 100 \% \\
& K d=0,068121 \times 100 \% \\
& K d=6.8121 \%
\end{aligned}
$$

Kesimpulannya berarti Citra Merek terhadap keputusan pembelian mempunyai pengaruh sebesar
$6.8121 \%$, sedangkan sisanya $93.1879 \%$ dipengaruhi oleh faktor lain yang tidak penulis teliti seperti harga, lokasi dan promosi. Nilai $6.8121 \%$ menunjukkan bahwa pengaruh Citra merek Positif/ Signifikan terhadap keputusan pembelian sepeda motor Suzuki New Satria FU150 di PT. Indotama Motorika Sintang. Hal ini dapat dilihat pada pedoman interpretasi koefisien determinasi pada tabel 3.13 di bawah ini 
Tabel 13 Pedoman Interpretasi Koefisien Determinasi

\begin{tabular}{|c|l}
\hline Pernyataan & \multicolumn{1}{|c}{ Keterangan } \\
\hline$>4 \%$ & Pengaruh Rendah Sekali \\
\hline $\mathbf{5 \%}-\mathbf{1 6 \%}$ & Pengaruh Rendah Tapi Pasti \\
\hline $17 \%-49 \%$ & Pengaruh Cukup Berarti \\
\hline $50 \%-81 \%$ & Pengaruh Tinggi atau Kuat \\
\hline$>80 \%$ & Pangaruh Tinggi Sekali \\
\hline
\end{tabular}

Sumber : Supranto (2001)

Dalam penelitian ini dilakukan uji hipotesis, yaitu untuk menentukan ada tidaknya pengaruh citra merek sebagai variabel bebas terhadap keputusan pembelian sebagai variabel terikat. Dengan memperhatikan karakteristik variabel yang akan diuji, berdasarkan perumusan hipotesis adalah sebagai berikut:

H0 : $\tilde{n}=0 ; \quad$ Ho ditolak, artinya tidak terdapat pengaruh yang signifikan antara citra merek terhadap keputusan pembelian

H1 : $\tilde{n}$ ““ $0 ;$ H1 diterima, artinya terdapat pengaruh yang signifikan antara citra merek terhadap keputusan pembelian

Untuk mengetahui ditolak atau tidaknya dapat dinyatakan dengan kriteria sebagai berikut :

Bila $\mathrm{t}$ hitung $>\mathrm{t}$ tabel, maka H0 ditolak dan H1 diterima.

Bila $\mathrm{t}$ hitung $<\mathrm{t}$ tabel, maka H0 diterima dan $\mathrm{H} 1$ ditolak.

Untuk menguji hipotesis yang penulis kemukakan dapat diterima, maka dilakukan pengujian uji $t$ dengan persamaan di bawah ini :

$$
t=r \frac{(n-2)}{" 1-r^{2}}
$$

Dimana:

$\mathrm{t}=$ Probabilitas

$r=$ Koefisien Korelasi Pearson

$\mathrm{n}=$ Jumlah Responden.

Kriteria pengujian adalah $\mathrm{H}_{0}$ jika harga dari rumus di atas (t hitung) yang didapat dari tabel distribusi $t$ dengan $\ddot{U}=0.05(5 \%)$ untuk mengetahui diterima atau ditolak, dinyatakan melalui kriteria yang sesuai dengan yang dikemukakan Umar (2000) sebagai berikut:

\section{a. Jika $\mathrm{t}$ _table $>\mathrm{t}$ hitung}

Maka $\mathrm{H}_{0}$ ada pada daerah penerimaan, berarti $\mathrm{H}_{1}$ diterima atau citra merek tidak berpengaruh terhadap keputusan pembelian.

\section{b. Jika $t$ tabel $<\mathrm{t}$ hitung}

Maka $\mathrm{H}_{0}$ terdapat pada daerah penolakan, berarti $\mathrm{H}_{1}$ diterima atau citra merek berpengaruh terhadap keputusan pembelian.

Di bawah ini adalah penghitungan uji signifikasi :

$$
\begin{aligned}
& \mathrm{t}=\mathrm{r} \frac{\text { “(n-2) }}{\text { "1- } \mathrm{r}^{2}} \\
& \mathrm{t}=0.261 \frac{\text { “(60-2) }}{" 1-0.261^{2}}
\end{aligned}
$$

$$
\mathbf{t}=\mathbf{2 . 1 3 3}
$$

Uraian pengujian hioptesis sebagai berikut :

Rs $=0.261$

$\ddot{\mathrm{U}}=0.05$

$\mathrm{n}=60$

Derajat kebebasan $(\mathrm{dk})=\mathrm{n}-2$

$$
=60-2=58
$$

Karena $\mathrm{dk}=58$ terletak antara $40-60$ dilihat dari hasil $\mathrm{t}$ tabel, maka untuk mendapatkan nilait tabel harus dilakukan interpolasi dengan rumus sebagai berikut :

$$
\begin{aligned}
& t 58=t 60-\frac{\mathrm{dk}-60}{60-40} \quad(t 40-t 60) \\
& t 58=2.00-\frac{58-60}{60-40} \quad(2.02-2,00) \\
& t 58=2.00-0,9(0.02) \\
& t 58=1,296-0,018
\end{aligned}
$$$$
\text { t58 }=1,278 \text { (nilai t tabel) }
$$

$\mathrm{t}$ hitung $>\mathrm{t}$ tabel $=2.113>1,278$

Kriteria :

Bila thitung $<\mathrm{t}$ tabel, maka Ho diterima

Bila thitung $>\mathrm{t}$ tabel, maka Ho ditolak

Thitung $(2,113)>t$ tabel $(1.278)$ maka Ho ditolak $\mathrm{H}_{1}$ diterima, yang penulis gambarkan pada gambar berikut ini: 


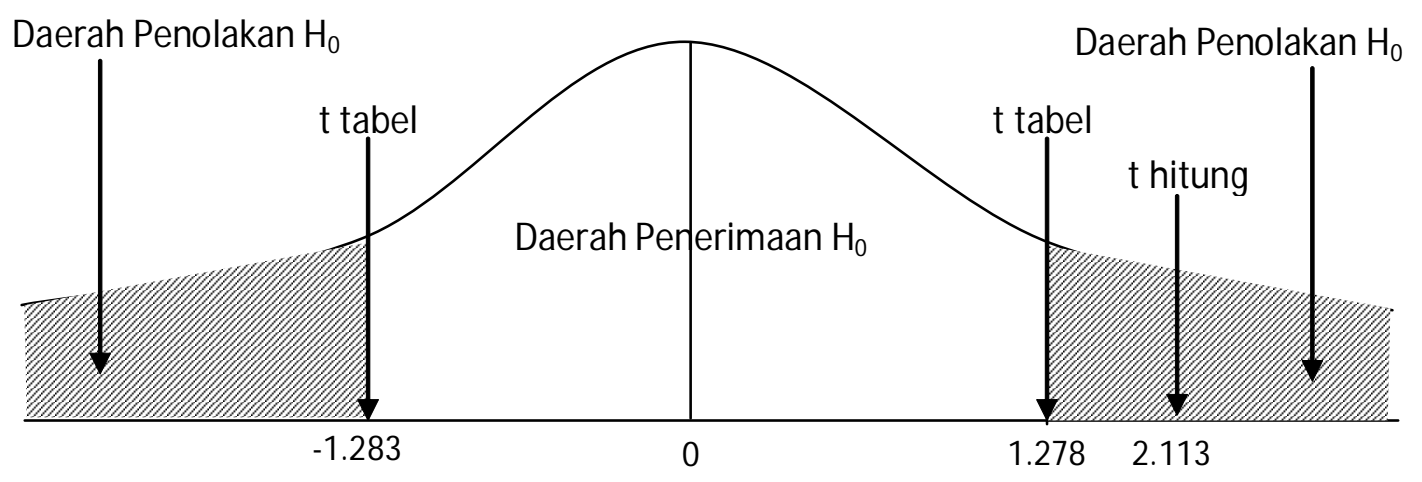

Dari gambar diatas dapat terlihat bahwa $\mathrm{t}$ hitung jatuh di daerah penolakan $\mathrm{H}_{0}$, ini berarti $\mathrm{H}_{1}$ diterima. Sehingga dapat dikatakan bahwa benar adanya pengaruh citra merek terhadap keputusan pembelian.

\section{KESIMPULAN DAN SARAN}

Berdasarkan hasil penelitian yang penulis lakukan mengenai pengaruh Citra Merek Suzuki New Satria FU150 terhadap Keputusan Pembelian pada PT. Indotama Motorika Sintang dapat disimpulkan bahwa tanggapan responden atas Citra Merek pada PT. Indotama Motorika Sintang pada saat ini dikatakan sangat baik yang diambil dari 4 (empat) indikator yaitu recognition, reputation, affinity, loyalty. Skor total tanggapan respondenpun citra merek mempunyai dorongan yang sangat baik yakni sebesar 91,37\% masuk dalam kriteria sangat baik. Tingkat keputusan pembelian sepeda motor Suzuki New Satria FU150 pada PT. Indotama Motorika Sintang pada saat ini adalah Tinggi yang diambil dari lima indikator yaitu pengenalan masalah, pencarian informasi, pengevaluasian alternatif, keputusan pembelian dan perilaku setelah pembelian. Dimana dari ke lima indikator tersebut memiliki skor total tanggapan responden tentang keputusan pembelian yang konsumen lakukan yaitu sebesar $84.52 \%$. Citra Merek mempunyai pengaruh yang cukup berarti, positif dan signifikan terhadap keputusan pembelian sepeda motor Suzuki New Satria FU150 di PT. Indotama Motorika Sintang. Besarnya pengaruh Citra Merek terhadap keputusan pembelian yaitu sebesar $6.8121 \%$ sedangkan sisanya senilai $93.1879 \%$ dipengaruhi oleh faktor lain yang penulis tidak teliti seperti perikanan, promosi, lokasi.

Dengan demikian disarankan sebaiknya Citra Merek Suzuki New Satria FU150 yang sudah mempunyai citra yang sangat baik tersebut harus tetap dipertahankan dan disempurnakan agar konsumen yang telah ada tetap bertahan dan konsumen terus meningkat. Sebaiknya keputusan pembelian sepeda motor Suzuki New Satria FU150 pada PT. Indotama Motorika Sintang tinggi terus ditingkatkan dengan cara menempatkan karakter produk, menyampaikan karakter produk dengan cara yang berbeda, memberikan kekuatan emosional yang lebih dari sekedar citra mental. Harus ditingkatkan agar tingkat keputusan pembelian meningkat. Sebaiknya PT. Indotama Motorika Sintang lebih memperhatikan faktor lain diluar Cira Merk yang cukup berpengaruh dalam menentukan keputusan konsumen dalam melakukan pembelian sepeda motor Suzuki New Satria FU150.

\section{DAFTAR PUSTAKA}

Husein, 2005. Riset Pemasaran dan Perilaku Konsumen, Jakarta : PT. Gramedia Pustaka Utama

Kertajaya, 2000. Marketing Plus 2000: Siasat Memenangkan Persaingan Global. Jakarta: PT. Gramedia Pustaka Utama.

Kotler dan Armstrong, 2004. Dasar-dasar Pemasaran (edisi kesembilan). Jakarta: PT. Indeks.

Kotler, 2003. Manajemen Pemasaran, Jilid V, Edisi Milenium, Jakarta: PT. Prebalindo.

Kotler, 2005. Manajemen Pemasaran. Edisi Kesebelas. Diterjemahkan oleh Benyamin Molan. Jilid 2. Jakarta : Indeks.

Nasution dan Usman, 2006. Proses Penelitian Kuantitatif. Jakarta BPFE-UI

Poeradisastra, 2005. Kepuasan Pelanggan ketika sekadar layanan tak lagi memuaskan, Majalah SWA No. 21 Edisi XXVII, 3-12 Oktober 2011

Rangkuti, 2002. The Power Of Brand. Jakarta : PT. Gramedi Pustaka Utama.

Solihin,Ismail. 2004. Kamus Pemasaran. Bandung: Pustaka

Sugiyono, 2008. Metode Penelitian Bisnis. Bandung: Alfabeta.

Umar, 2005. Riset Pemasaran dan Perilaku Konsumen. Jakarta: PT. Gramedia Pustaka Utama. 